\title{
Two channel passive visualization of a nitinol guidewire with iron markers
}

\author{
Adrienne E Campbell-Washburn ${ }^{1 *}$, Toby Rogers ${ }^{1}$, Burcu Basar ${ }^{1,2}$, Merdim Sonmez ${ }^{1}$, Ozgur Kocaturk ${ }^{1}$, \\ Robert J Lederman ${ }^{1}$, Michael Hansen ${ }^{1}$, Anthony Z Faranesh ${ }^{1}$ \\ From 18th Annual SCMR Scientific Sessions \\ Nice, France. 4-7 February 2015
}

\section{Background}

MRI-guidance for cardiovascular catheterization is appealing to reduce ionizing radiation exposure and to enable novel procedures. "Active" guidewire-antennas for MRI-guided procedures are often designed such that the tip and shaft have distinct signals [1] to improve navigation and to make it obvious when the tip moves out of plane. Here we present a method to isolate the signal from iron markers, and produce a two channel color overlay for visualizing the shaft and tip of a nitinol guidewire.

\section{Methods}

Three iron-oxide markers were added to a commercially available 0.035 " nitinol guidewire (Nitrex, Covidien, Plymouth, MN). Gradient echo spiral imaging (8 interleaves, $\mathrm{TE} / \mathrm{TR}=0.86 / 10 \mathrm{~ms}$, flip angle $=10^{\circ}$ ) was performed on a $1.5 \mathrm{~T}$ MRI scanner (Aera, Siemens, Erlangen, Germany). Image processing was performed in MATLAB (R2013a, Mathworks, Natick, MA).

\section{Channel 1 - Iron markers}

Off-resonance spins, such as those created by the iron markers, cause blurring in spiral images [2]. Images were reconstructed at two frequencies, on-resonance and $200 \mathrm{~Hz}$ off-resonance. A subtraction of the two image reconstructions [(on-off)/on] generated a characteristic dark-bright-dark pattern from the iron markers, which was detected by a specifically designed convolution kernel.

\footnotetext{
'Division of Intramural Research, Cardiovascular and Pulmonary Branch, National Heart Lung and Blood Institute, National Institutes of Health, Bethesda, MD, USA

Full list of author information is available at the end of the article
}

\section{Channel 2 - Nitinol guidewire}

Through-slice dephasing [3] was applied to alternating frames to generate a positive contrast image, where the nitinol guidewire appears bright with background signal suppressed, from which the guidewire signal was isolated.

\section{Results}

Spiral images were generated at $80 \mathrm{~ms} /$ frame. Phantom images show the iron marker signal changing with reconstruction frequency (Figure 1). In vivo, the guidewire was inserted transfemorally to the left ventricle of one pig and imaged. The iron marker signal and nitinol guidewire signal were overlaid on the anatomical image in different colors (Figure 2).

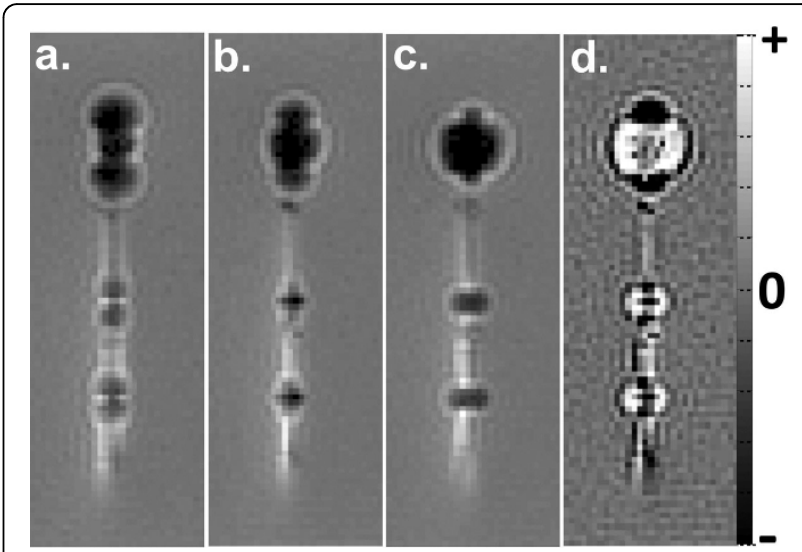

Figure 1 Phantom images of the nitinol guidewire with three ironoxide markers (one large, two small) demonstrating reconstruction at $-200 \mathrm{~Hz}$ off-resonance (a), on-resonance (b) and $+200 \mathrm{~Hz}$ offresonance (c). Image subtraction (d) creates a characteristic darkbright-dark pattern from the iron markers. 


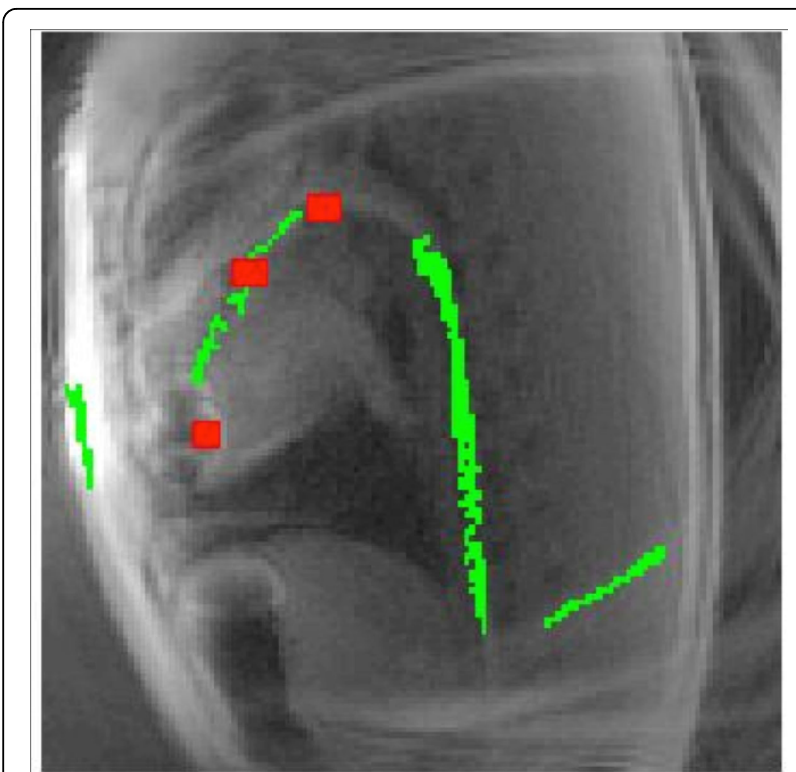

Figure 2 Two channel passive visualization using isolated signal from the iron markers (red) and nitinol guidewire (green).

\section{Conclusions}

Here, we have presented a proof-of-concept experiment demonstrating two channel color overlay of a passive nitinol guidewire with iron markers. A new method utilizing off-resonance reconstruction of spiral images was applied to isolate the iron markers and depict them with a unique imaging signature to enhance usability. Future work will optimize the method to ensure robust detection of the marker signal.

\section{Funding}

This work was supported by the NHLBI DIR (Z01HL006039-01, Z01-HL005062-08).

\section{Authors' details}

${ }^{1}$ Division of Intramural Research, Cardiovascular and Pulmonary Branch, National Heart Lung and Blood Institute, National Institutes of Health, Bethesda, MD, USA. Institute of Biomedical Engineering, Bogazici University, Istanbul, Turkey.

Published: 3 February 2015

\section{References}

1. Kocaturk O, et al: An Active two Channel 0.035" Guidewire for Interventional Cardiovascular MRI. JMRI 2009, 30:461-465.

2. Man LC, et al: Multifrequency interpolation for fast off-resonance correction. MRM 1997, 37:785-792.

3. Seppenwoolde $\mathrm{H}$, et al: Passive Tracking Exploiting Local Signal Conservation: The White Marker Phenomenon. MRM 2003, 50:784-790.

\section{doi:10.1186/1532-429X-17-S1-P236}

Cite this article as: Campbell-Washburn et al: Two channel passive visualization of a nitinol guidewire with iron markers. Journal of Cardiovascular Magnetic Resonance 2015 17(Suppl 1):P236.

\section{Submit your next manuscript to BioMed Central and take full advantage of:}

- Convenient online submission

- Thorough peer review

- No space constraints or color figure charges

- Immediate publication on acceptance

- Inclusion in PubMed, CAS, Scopus and Google Scholar

- Research which is freely available for redistribution
C Biomed Central 